J. Perinat. Med. 8 (1980) 142

\section{The accuracy of abdominal ECG for fetal electronic monitoring}

\author{
Thore Solum*, Ingemar Ingemarsson*, Åke Nygren** \\ *Dept. of Obstetrics and Gynaecology, University Hospital of Lund, Lund, Sweden \\ **Dept. of Electrical Measurements, Lund Institute of Technology, Lund, Sweden
}

\section{Introduction}

Since 1974 abdominal electrocardiography has been available as optional equipment on cardiotocographs. Besides phonocardiography and ultrasound cardiography it is one of the methods for indirect cardiography.

To allow calculations of the instantaneous fetal heart rate, the trigger pulse must have a constant quality, for instance the R-wave in the ECGcomplex. This is obtained in direct cardiography via the scalp electrode.

In abdominal electrocardiography the trigger pulse is the fetal R-wave as in direct electrocardiography which makes a registration of the instantaneous fetal heart possible. However, the maternal ECGcomplex will also be recorded and interfere with the fetal ECG-complex. When this happens a substitution for the fetal complex is made in the cardiotocograph allowing a continuous recording of the fetal heart rate.

The aim of this study was to investigate the agreement between direct and abdominal fetal electrocardiography, to calculate the frequency of substituted fetal heart beats by abdominal electrocardiography and to compare short term variability and long term variability recorded by direct and abdominal method.

\section{Material and methods}

Fetal heart rate registrations from nine patients in the first stage of labour are included in the study.

\section{Curriculum vitae}

Dr. THORE SOLUM was born in Tönsberg, Norway, in September 1944. He studied medicine in Göttingen from 1964 to 1969 . He trained gynaecology and obstetrics at the Dept. of Gynaecology and Obstetrics, University Hospital, Lund, Sweden, from 1971 to 1976 when he became specialist in the subject. His main interest is obstetrics and fetal monitoring.

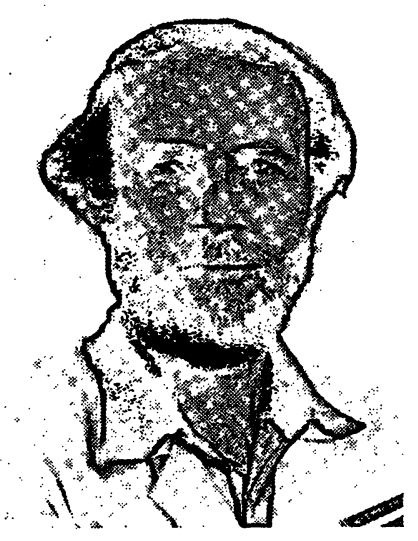

The fetal heart rate was monitored by abdominal (aFECG) and direct (dFECG) electrocardiography using two cardiotocographs 8030 A from HEwLETT PACKARD. A third cardiotocograph of the same type registered the maternal heart rate via electrodes on the chest (MECG). All signals were simultaneously recorded on three different channels on a 4 channel analogue FM type-recorder (Hewlett Packard 3960). The recorded signal was the $120 \mathrm{~ms}$, $+6.5 \mathrm{~V}$ flash pulse which is accessible in the rear system connector pin $\mathrm{D}$ and A (digital ground). This signal is triggered by a valid heart beat or a substitution made by the cardiotocograph.

The HP 8030 A makes two types of substitutions:

a. If, after two consecutive fetal pulses, the next pulse is missing because of technical problems, one and only one substitution is made. 
b. If the fetal pulse is masked by the maternal ECG a substitution is made. A fetal pulse will be masked if it occurs closer than $190 \mathrm{~ms}$ before the maternal R-wave or less than $75 \mathrm{~ms}$ after it (Fig. 1).

To make this substitution possible, the output from the aFECG must be delayed. It is delayed longer than the maximum permissible change in the heart period (14 bpm change from 50$64 \mathrm{bpm}=262,5 \mathrm{~ms}$ ) and shorter than the shortest duration of a period $(210 \mathrm{bpm}=285,7 \mathrm{~ms})$.

The chosen delay according to the HewLetT PACKARD operation instructions is $272 \mathrm{~ms} \pm 2 \mathrm{~ms}$. The above mentioned substitutions do only occur in aFECG and not in dFECG or MECG.

To transfer the information from the tape into the computer, three 15-bit digital counters were built. The calculations were carried out on the Data General Nova ${ }^{\circledR} 2.10$ system (Fig. 2).
The three counters measured, with $1 \mathrm{~ms}$ resolution, the beat-to-beat distance in the aFECG, dFECG and MECG channels simultaneously using the same clock to ensure that no time errors would be introduced between the channels. The beat-tobeat times were stored on three separate disc files for future calculations. The file with beat-to-beat times from aFECG was corrected with a delay of approximately $270 \mathrm{~ms}$ at the beginning.

Only aFECG records with practically no failure or artifacts (Fig. 3) were included. In all calculations we have used the original data and only extracted parts where the aFECG is missing due to substitution a.

Within a window of $40 \mathrm{~ms}$ around the aFECG pulses, the dFECG channel was checked for pulses and the differences in time registered. In the next step the number of substituted fetal heart beats was calculated by comparing the channel for

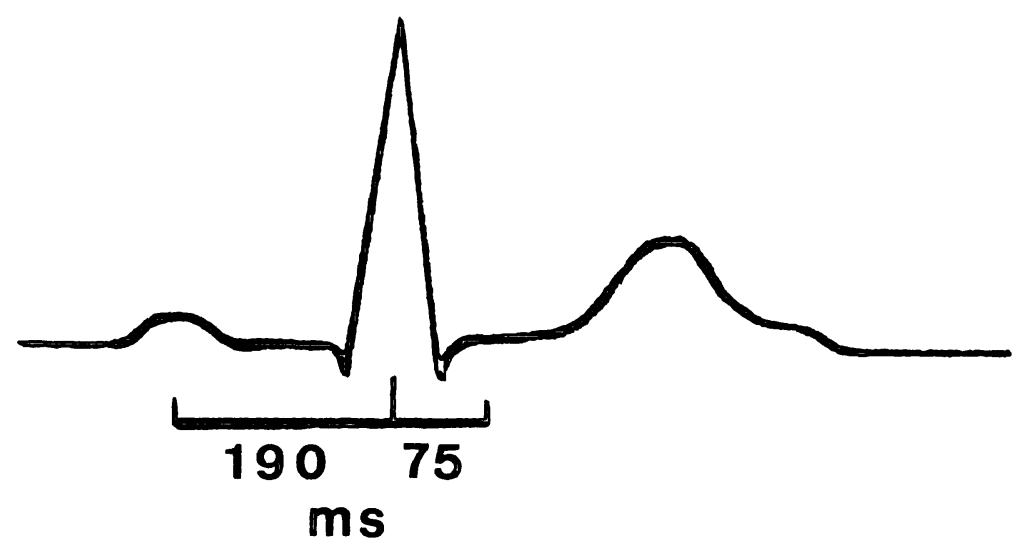

Fig. 1. The fetal trigger will be ignored when occurring within $190 \mathrm{~ms}$ before and $75 \mathrm{~ms}$ after the maternal R-wave. Instead a substitution will be made.

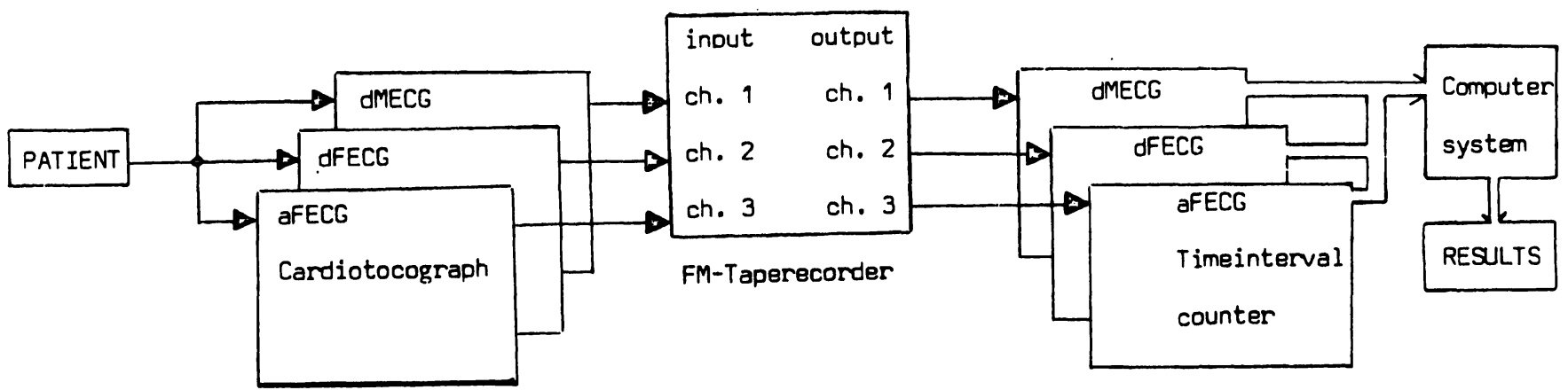

Fig. 2. Using three cardiotocographs (HP $8030 \mathrm{~A}$ ) the fetal and maternal heart beats were stored on a tape. An analoguedigital conversion was done and the information calculated in a computer system. 
dMECG and AFECG within a window of $190 \mathrm{~ms}$ before and $75 \mathrm{~ms}$ after the maternal pulse. The last step was to compare the short and long term variability. For calculation of these, the index of DE HAAN et al. [4] was chosen. The first comparison was done tolerating a difference of one beat/min between aFECG and dFECG at a frequency of 140 beats/min. In a second comparison two beats/min were tolerated. The results are expressed by means of the correlation coefficient.

\section{Results}

Nine patients at term were' included in the study. All patients were in the first stage of labour. In mean the patients were registered for 24 minutes. A total of 30651 beats were recorded with dFECG. Visually all the aFECG-tracings were of very good quality (Fig. 3). However, the computerized comparison with dFECG showed that about $10 \%$ of the fetal heart beats were not registered by aFECG.



\section{Abdominal electrocardiography}

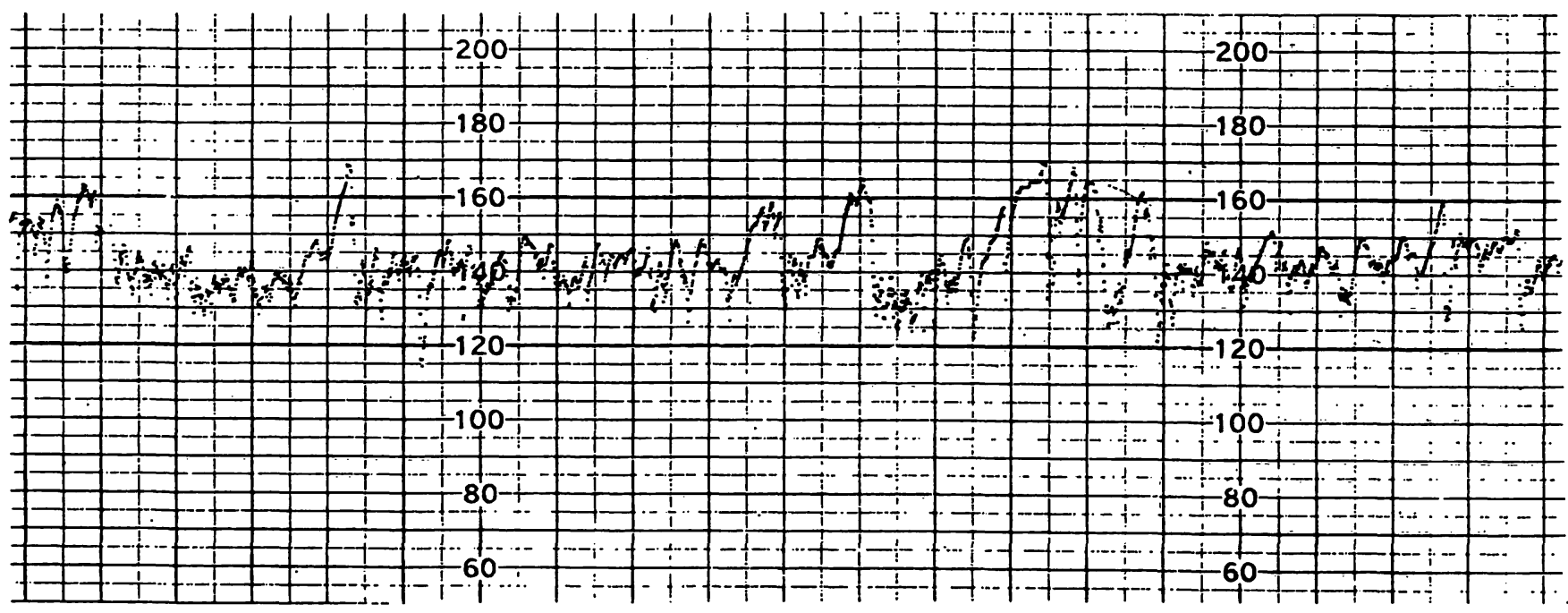

\section{Direct electrocardiography}

Fig. 3. Original records from patient no. 3. 
It means that a total of 27720 pulses were recorded from aFECG.

Within a window of $40 \mathrm{~ms}( \pm 20 \mathrm{~ms})$ around each of these pulses the dFECG-file was checked. In 99.2\% of the cases a corresponding dFECG-pulse could be found. In $98.5 \%$ of all recorded pulses they were within a window of $20 \mathrm{~ms}( \pm 10 \mathrm{~ms})$ (Fig. 4).

Depending on the maternal heart rate, the frequency of interference of maternal and fetal complexes was different. In mean it was $35 \%$ with a range of 27 to $46.5 \%$ (Tab. I).

The short term variability and the long term variability will not be exactly the same in aFECG and dFECG recordings because of the substitutions
Tab. I. The frequency of substituted fetal heart beats in aFECG due to interference between the maternal and fetal ECG-complexes for each patient included in the study (patient nr 3 had to be excluded because of problems with the electrodes recording the MECG).

\begin{tabular}{ll}
\hline Patient no. & Substitutions in \% \\
\hline & \\
1 & 26.8 \\
4 & 30.8 \\
5 & 38.8 \\
6 & 30.1 \\
7 & 38.1 \\
8 & 46.5 \\
9 & 34.5 \\
\hline
\end{tabular}

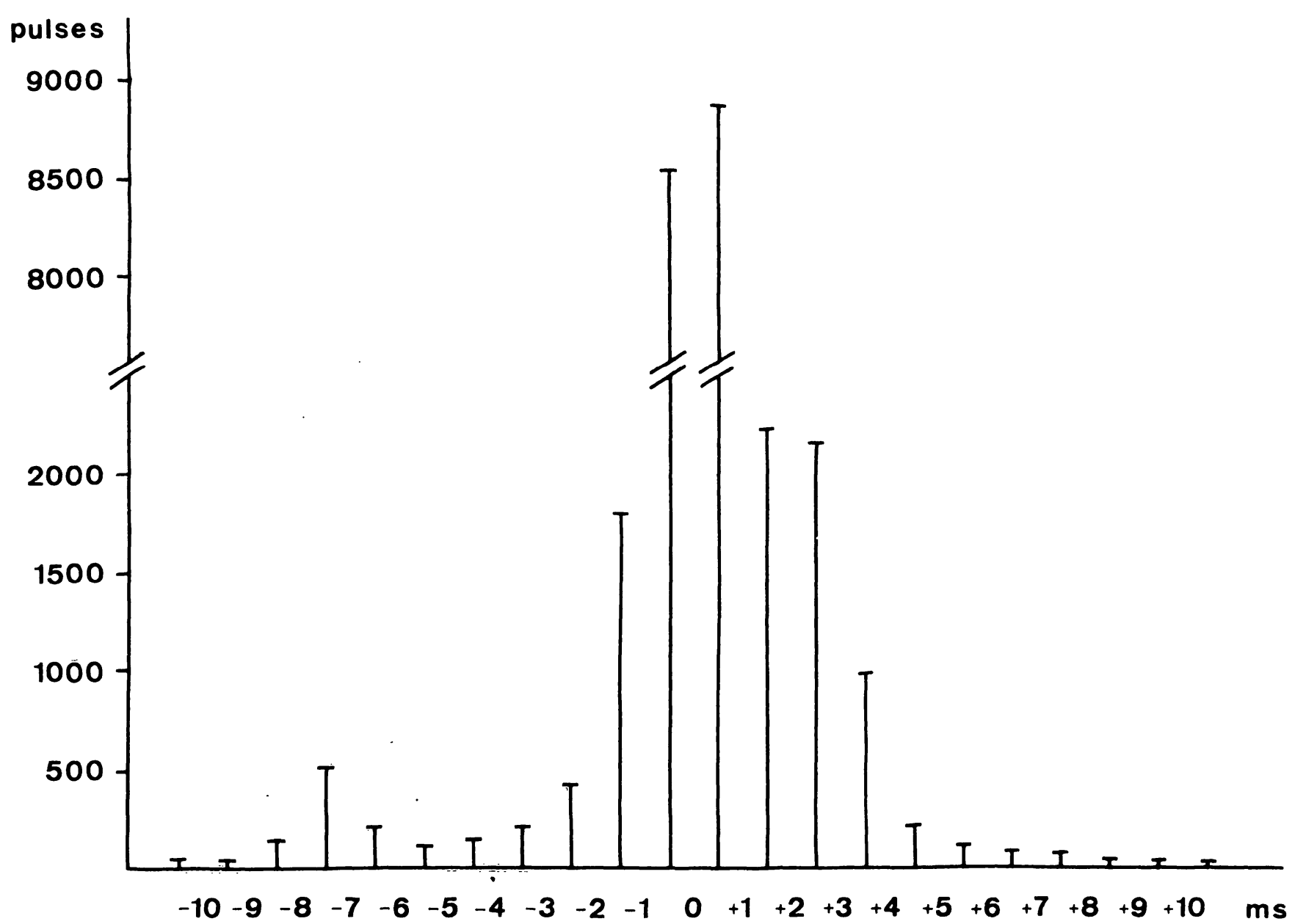

Fig. 4. The distribution of 27750 aFECG pulses around the mean point. The mean point is defined as the moment of the dFECG-pulse $+270 \mathrm{~ms}$. $98.5 \%$ of all pulses were found within $\pm 10 \mathrm{~ms}$ from the mean point. 
(Figs. 5 and 6). Allowing a maximum difference in short term variability of one beat/min between the aFECG and the dFECG, the correlation coefficient for all 27720 pulses was 0.75 . Allowing in the same manner, a difference of 2 beats/min the correlation coefficient was 0.91 (Tab. II).

Tab. II. The correlation of short term variability between aFECG and dFECG. The table shows the correlation coefficient for each patient. Correlation coefficients for a maximum difference of \pm 1 beat $/ \mathrm{min}$ and \pm 2 beats $/ \mathrm{min}$ are shown.

\begin{tabular}{lll}
\hline Patient number & \multicolumn{2}{l}{$\begin{array}{l}\text { Correlation coefficient } \\
\pm 1 \text { beat/min }\end{array}$} \\
\hline 1 & \pm 2 beats/min \\
2 & 0.719 & 0.887 \\
3 & 0.725 & 0.848 \\
4 & 0.830 & 0.916 \\
5 & 0.773 & 0.962 \\
6 & 0.838 & 0.938 \\
7 & 0.643 & 0.824 \\
8 & 0.748 & 0.959 \\
9 & 0.747 & 0.893 \\
\hline
\end{tabular}

The long range variability by aFECG and dFECG was also compared. Even for the long range variability a difference of one and two beats was allowed. The correlation coefficients were 0.94 and 0.98 respectively (Tab. III).

Tab. III. The correlation of long term variability between aFECG and dFECG. The table shows the correlation coefficient for each patient. Correlation coefficients for a maximum difference of \pm 1 beat $/ \mathrm{min}$ and \pm 2 beats $/ \mathrm{min}$ are shown.

\begin{tabular}{|c|c|c|}
\hline \multirow[t]{2}{*}{ Patient number } & \multicolumn{2}{|c|}{ Correlation coefficient } \\
\hline & 1 beat $/ \mathrm{min}$ & 2 beats $/ \mathrm{min}$ \\
\hline 1 & 0.923 & 0.979 \\
\hline 2 & 0.907 & 0.943 \\
\hline 3 & 0.945 & 0.974 \\
\hline 4 & 0.978 & 0.998 \\
\hline 5 & 0.965 & 0.985 \\
\hline 6 & 0.867 & 0.950 \\
\hline 7 & 0.978 & 0.997 \\
\hline 8 & 0.929 & 0.975 \\
\hline 9 & 0.944 & 0.981 \\
\hline
\end{tabular}

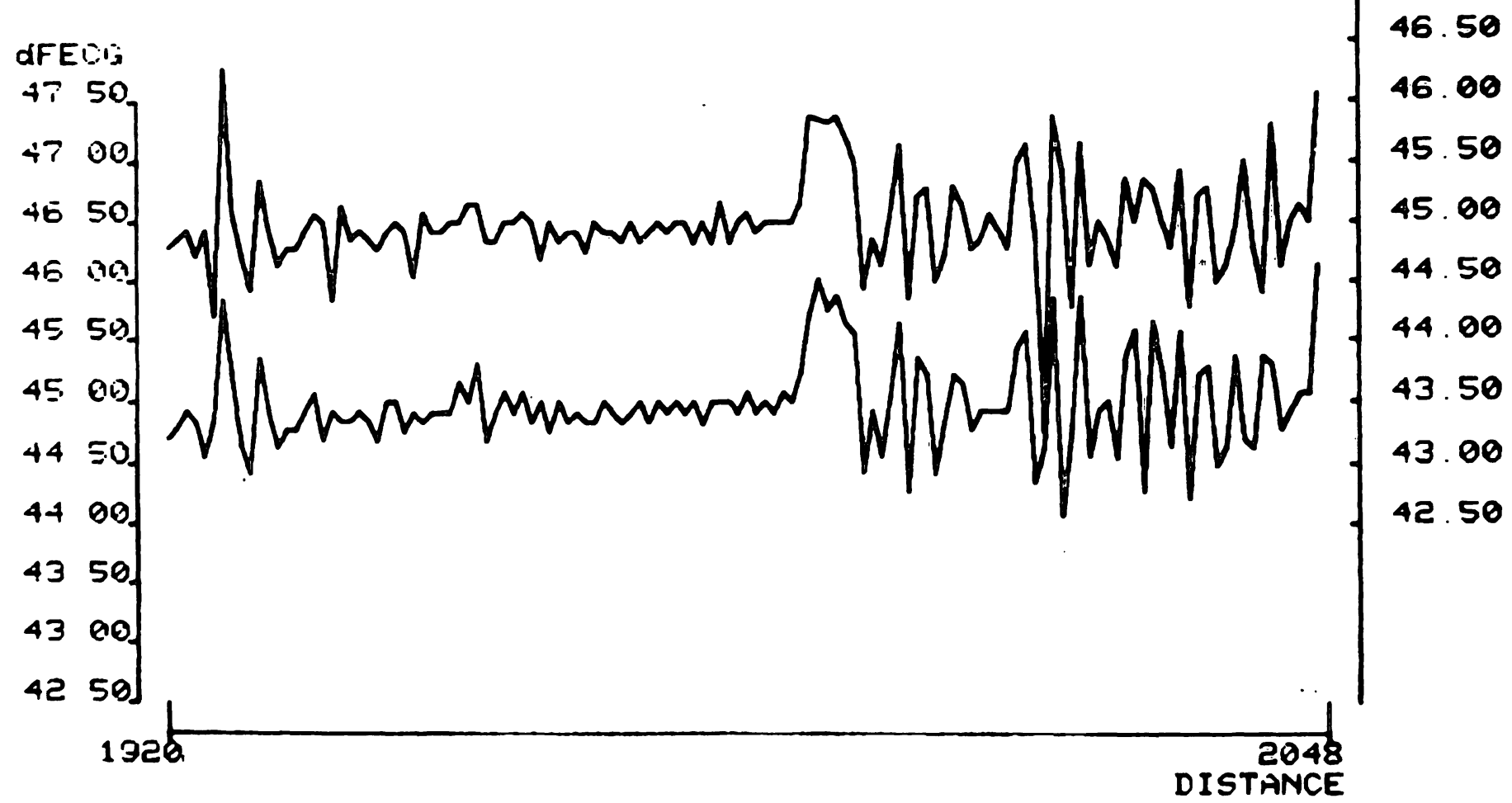

Fig. 5. A display of the short term variability made by the computer. The abscissa shows a distance of 128 beats (intervals). The left ordinate represents the different angles of the argument for dFECG according to the definition of DE HAAN. The right ordinate shows the same for aFECG. (0.204 degrees mean a difference in short term variability of $1 \mathrm{beat} / \mathrm{min}$ by a frequency of 140 beats/min.) 


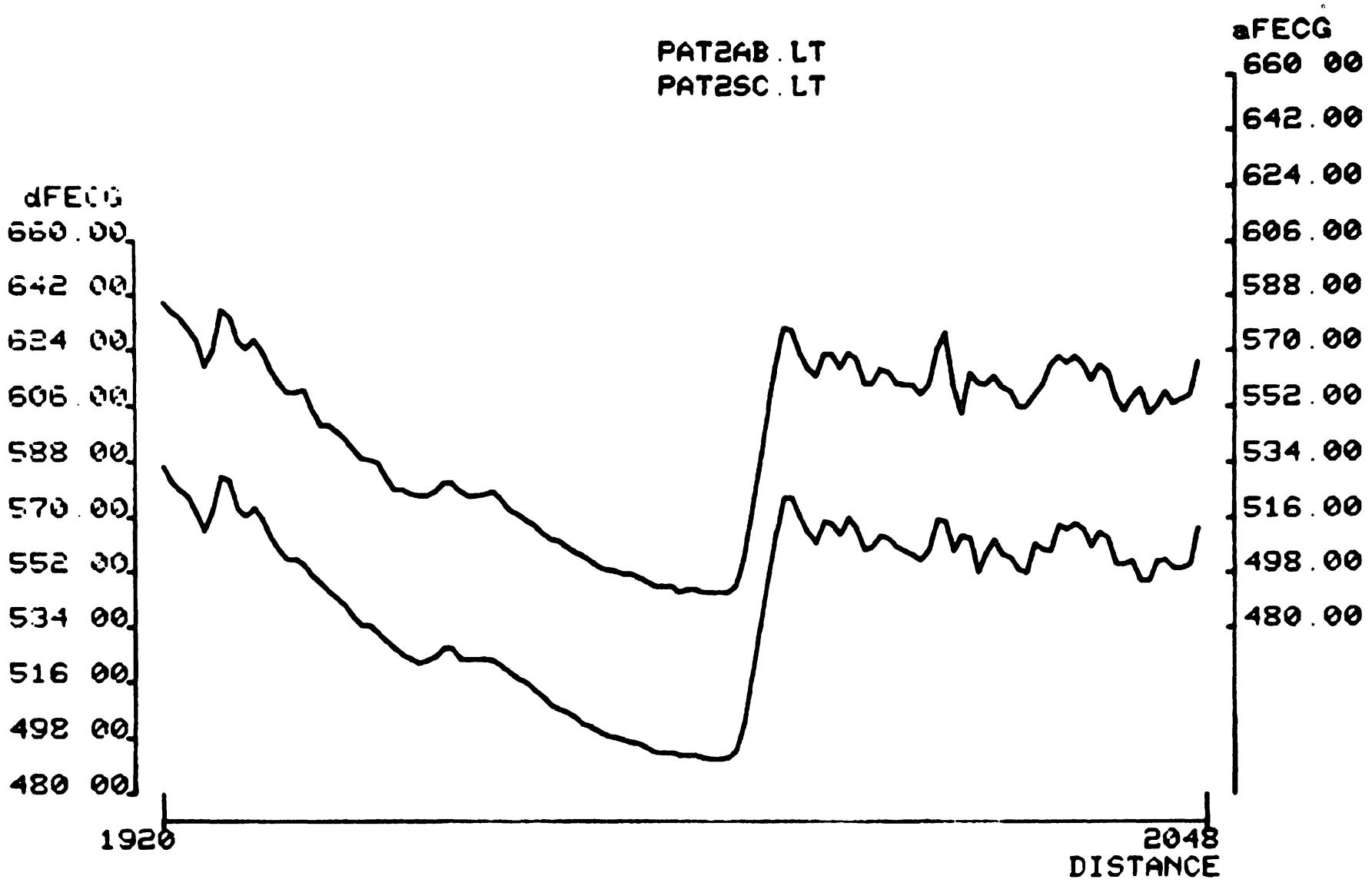

Fig. 6. A display of the long term variability made by the computer. The abscissa shows a distance of 128 beats (intervals). The left ordinate represents the different moduli for dFECG according to the definition of DE HAAN. The right ordinate shows the same for aFECG. $(3.4 \mathrm{~ms}$ mean a difference in long term variability of 1 beat/min by a frequency of 140 beats/min.)

\section{Discussion}

Previous studies have shown that the aFECG will give a low number of clinically useful tracings before the 32 th -34 th week of pregnancy $[1,2$, 6]. In antenatal cardiotocography the use of abdominal FECG therefore seems to be of value in the last weeks of pregnancy when the number of tracings of good quality exceeds 60 to $70 \%[2,5$, $6,9]$. This study shows that under optimal conditions in term pregnancies about $90 \%$ of the fetal heart beats will be registered by a aFECG.

A low short term variability is thought to reflect impairment of the central nervous regulation of the heart frequency [3]. It is therefore important to have an indirect method for fetal heart rate monitoring which will give a reliable registration of the instantaneous fetal heart rate in the antenatal period. Using aFECG the substitutions of fetal heart beats will, according to the present study, occur in one third of the cases. It was therefore not quite obvious that the true instantaneous fetal heart rate could be monitored by aFECG. If the quality of the substitutions is good, however, it should be possible to imitate the instantaneous heart rate well enough to allow calculations of both short term and long term variability.

A visual comparison of graphs obtained simultaneously by aFECG and dFECG shows no greater difference (Fig. 3) [2,8]. The present study shows that $98.5 \%$ of the registered pulses by aFECG differ at most $10 \mathrm{~ms}$ from the pulses registered by dFECG. Furthermore the correlation between the two methods is good concerning both short term and long term variability. This agrees with one previous report [7].

In most obstetric departments the cardiotocograms are studied visually. In this way the beat-to-beat 
variability cannot be judged. Instead the so called band width of the tracings is studied which rather reflect the long term variability [4]. According to the present study it is concluded that the aFECG will give information reliable enough to judge fetal heart rate variability both antenatally and intrapartum.

\section{Summary}

To allow calculation of the beat-to-beat variability in fetal electrocardiography the trigger signal has to be of good quality. The aim of this study was to investigate the quality of the abdominal fetal electrocardiography (aFECG), and compare the short term and long term variability registered by this method with the direct fetal electrocardiography (dFECG).

With three cardiotocographs the aFECG, the dFECG and the maternal ECG were registered simultaneously and stored on a magnetic tape. After analogue-digital conversion, the information was calculated in a computer system.

The variability registered by aFECG and dFECG was compared allowing a difference of both one beat and two beats/min.
Because of the difficulties in judging the short term variability visually, computerized calculations are now available. They are'based upon the dFECG. In the antenatal period when it is not possible to use the dFECG, it should be possible to use aFECG as a base also for computer analysis of fetal heart rate variability.
From nine patients in early labour 30651 heart beats were registered by dFECG. By aFECG 27720 beats were registered. Within a window of $\pm 10 \mathrm{~ms} 98.5 \%$ of all pulses registered by aFECG were found.

The correlation coefficients for short term variability were 0.75 and 0.91 . For long term variability the correlation coefficients were 0.94 and 0.98 .

To allow calculations of the short term variability the registration of the instantaneous fetal heart rate is necessary. In the antenatal period only indirect methods for electrocardiography are possible. The present report shows that with the abdominal electrocardiography the short term and long term variability can be judged. The quality of the registrations is good enough to allow computer calculations of the information.

Keywords: Abdominal fetal electrocardiography, computer, fetal heart, instantaneous fetal heart rate, short term variability.

\section{Zusammenfassung}

In der foetalen Elektrokardiographie muß das TriggerSignal von guter Qualität sein, um die Mikrofluktuation beurteilen zu können. Das Ziel dieses Berichtes war, die Qualität der abdominellen foetalen Elektrokardiographie (aFECG) zu untersuchen und die Mikro- und Makrofluktuation mit denen der direkten foetalen Elektrokardiographie (dFECG) zu vergleichen.

Mit Hilfe von drei Kardiotokographen wurden gleichzeitig aFECG, dFECG und maternelles EKG aufgezeichnet und auf einem Tonband gespeichert. Die Informationen wurden in einem Datasystem berechnet. Die Fluktuation der aFECG und dFECG wurde mit einem Unterschied von sowohl einem Schlag als zwei Schlägen/Min mit einander verglichen.

Von neun Patientinnen in der Eröffnungsperiode wurden 30651 Herzschläge mit dFECG registriert. Mit aFECG wurden 27720 Herzschläge registriert. Innerhalb eines Fenster von $\pm 10 \mathrm{~ms}$ wurden $98.5 \%$ aller Pulse, die durch aFECG registriert waren, gefunden.

Die Korrelationskoeffizienten der Mikrofluktuation waren 0.75 und 0.91, für die Makrofluktuation 0.94 und 0.98.

Die Registrierung der instantanen foetalen Herzfrequenz ist notwendig, um die Mikrofluktuation zu berechnen. In der antenatalen Periode stehen nur indirekte Elektrokardiographie zur Verfügung. Der vorliegende Bericht zeigt, daß mit abdomineller, foetaler Elektrokardiographie sowohl Mikro- als Makrofluktuation beurteilt werden können. Die Qualität der Registrierungen ist ausreichend, um eine Computerbasierte Berechnung der Informationen zu erlauben. 
Résumé

La fiabilité de 1'ECG transabdominale dans la surveillance électronique du foetus.

Afin d'apprécier les microfluctuations il est nécéssaire que le signal Trigger soit de bonne qualité dans l'éléctrocardiographie foetale. Le propos de ce travail est d'éxaminer la qualité de l'éléctrocardiographie foetale transabdominale (aFECG) et de comparer la micro- et macrofluctuation avec celles de l'éléctrocardiographie foetale directe. (dFECG).

A l'aide de trois cardiotocographes nous avons enregistré simultanément et sur cassette les aFECG, dFECG et l'ECG maternel. L'analyse des informations a été réalisée à l'aide d'un computer. La variabilité de l'aFECG et du dFECG a été comparée en prenant en considération une différence d'un et de deux battements/min.
30651 battement cardiaques ont été enregistrés chez 9 parturientes en début de travail, ceci à l'aide du dFECG. L'aFECG enregistrati 27720 battements. A l'intérieur d'une fourchette de $\pm 10 \mathrm{~ms}$ l'on retrouvait $98.5 \%$ de l'ensemble des battements enregistrés à l'aide de l'aFECG. Les coéfficients de corrélation des microvariabilités étaient de 0.75 et 0.91 . Ceux de la macrovariabilité étaient de 0.94 et 0.98 .

L'enregistrement de la fréquence cardiaque instantanée est nécéssaire pour l'établissement de la microvariabilité. Seule l'éléctrocardiographie indirecte est possible dans la période anténatale. Le présent travail montre qu'il est possible d'apprécier aussi bien la microque la macrovariabilité à l'aide de l'éléctrocardiographie foetale transabdominale. La qualité des enregistrements est suffisante pour permettre l'analyse des informations par ordinateur.

Mots-clés: Eléctrocardiographie foetale transabdominale, fréquence cardiaque foetale instantanée, microvariabilité ordinateur.

Acknowledgement: We thank Professor HELlMUTH HERTz, Head of the Dept. of Electrical Measurements of the Lund Institute of Technology for his kind support of the project.

\section{Bibliographie}

[1] BOLTE, A.: Die pränatale fetale Elektrokardiographie. Der Gynäkologe 2 (1969) 63

[2] BREUKER, K.-H., D. KHALILI-BRUNKLAUS, A. BOLTE: Das abdominale fetale EKG zur prä- und subpartualen Herzfrequenzanalyse. Arch. Gynäk. 221 (1976) 211

[3] GoODLIN, R. C.: Fetal cardiovascular responses to distress. Obstet. Gynec. 49 (1977) 371

[4] DEHAAN, J., J. H. VAN BEMMEL, B. VERSTEEG, A. F. L. VETH, L. A. M. STOLTE, J. JANSSENS, T. K. A. B. ESKES: Quantitative evaluation of fetal heart rate patterns. Europ. J. Obstet. Gynec 3 (1971) 95

[5] INGEMARSSON, I., N. RAABE, T. SOLUM: Abdominalt EKG för fosterövervakning. Läkartidningen 73 (1976) 4526

[6] JAUER, P.-CHR., J. HEINRICH, E. KOEPCKE, H. HOPP, G. SEIDENSCHNUR: Vergleichende Untersu- chungen zur Frage der Wertigkeit der Impulsaufnahmeverfahren der vorgeburtlichen Kardiotokographie. ZBl. Gynäk. 98 (1976) 990

[7] KARINIEMI, V.: Quantification of fetal heart rate variability by electro- and magnetocardiography. Thesis. University of Helsinki, Finland. Report TKKF-A308 (1977)

[8] KLÖCK, F. K., G. LAMBERTI, H. J. SCHULTE, B. LIEDTKE: Die Kardiotokographie mit dem externen fetalen EKG. In: SALING, E., J. W. DUDENHAUSEN (eds.): Perinatale Medizin, Bd. 3. Thieme, Stuttgart 1972

[9] KLÖCK, F. K., L. HARTMER: Die Kardiotokographie mit dem externen fetalen EKG im Vergleich zur Ultraschallkardiotokographie. Z. Geburtsh. u. Perinat. 181 (1977) 178

Received May 13, 1978. Revised August 22, 1979. Accepted January 21, 1980.
Dr. Thore Solum

Dept. of Obstet. and Gynec.

University of Lund

S-221 85 Lund/Sweden 